\title{
Using In Situ TEM Helium Implantation and Annealing to Study Cavity Nucleation and Growth
}

\author{
CAITLIN A. TAYLOR,${ }^{1}$ JOSHUA D. SUGAR ${ }^{2}$ DAVID B. ROBINSON,${ }^{2}$ \\ NORMAN C. BARTELT, ${ }^{2}$ RYAN B. SILLS, ${ }^{2,3}$ and KHALID HATTAR ${ }^{1,4}$
}

\author{
1.-Sandia National Laboratories, Albuquerque, NM 87185, USA. 2.-Sandia National \\ Laboratories, Livermore, CA 94551, USA. 3.-Rutgers University, Piscataway, NJ 08854, USA. \\ 4.-—e-mail: khattar@sandia.gov
}

\begin{abstract}
Noble gases are generated within solids in nuclear environments and coalesce to form gas stabilized voids or cavities. Ion implantation has become a prevalent technique for probing how gas accumulation affects microstructural and mechanical properties. Transmission electron microscopy (TEM) allows measurement of cavity density, size, and spatial distributions post-implantation. While post-implantation microstructural information is valuable for determining the physical origins of mechanical property degradation in these materials, dynamic microstructural changes can only be determined by in situ experimentation techniques. We present in situ TEM experiments performed on $\mathrm{Pd}$, a model face-centered cubic metal that reveals real-time cavity evolution dynamics. Observations of cavity nucleation and evolution under extreme environments are discussed.
\end{abstract}

\section{INTRODUCTION}

Materials designed for nuclear reactor environments must perform under extreme environmental conditions, including radiation damage, elevated temperature, and mechanical stress. Noble gas elements, especially $\mathrm{He}, \mathrm{Xe}$, and $\mathrm{Kr}$, are generated through nuclear reactions and are insoluble in most materials. These elements often coalesce to form gas-stabilized cavities inside metals and ceramics subject to radiation damage. Gas-stabilized cavities significantly degrade the mechanical properties of materials, so their behavior must be well characterized to accurately predict material performance. ${ }^{1-5}$ Experimentally, ion implantation has become a prevalent technique for probing gas accumulation effects on mechanical properties and for correlating microstructural and mechanical effects. ${ }^{6-10}$ Transmission electron microscopy (TEM) is ideal for quantifying radiation-induced cavity density, size, and spatial distribution because of the nanometer length scale of these features. ${ }^{11-15}$

Combining numerical simulations across a variety of length and time scales with experimental observations can yield a detailed understanding of: noble atom diffusion properties, the timeframe for cavity nucleation under various thermal and irradiation conditions, cavity growth mechanisms under varying initial defect and gas concentration states, and the time dependence on cavity growth mechanisms. ${ }^{16-23}$ While post-characterization of ion-implanted samples provides some data for validating simulations, the specifics of the evolution mechanisms can only be differentiated using in situ experimentation techniques that enable dynamical observations of microstructural changes.

Several in situ characterization techniques have been employed to characterize gas cavity behavior as a function of dose, time, or temperature, including elastic recoil detection, ${ }^{24}$ positron annihilation spectroscopy, ${ }^{25} \mathrm{TEM},{ }^{26,27}$ transient grating spectroscopy, ${ }^{28,29}$ and acoustic emission. ${ }^{29}$ We demonstrate the utility of in situ TEM ion implantation and annealing experiments for providing in situ time-dependent data on gas stabilized cavity evolution and growth in extreme environments and suggest how those data can motivate and aid validation of models that provide a mechanistic explanation for macroscopic physical phenomena. ${ }^{30}$ In situ TEM He implantation has previously been performed on several pure metals. ${ }^{31-41}$ In situ TEM annealing has been employed to determine cavity growth mechanisms in He-implanted metals. ${ }^{40,42-44}$ We present new experimental results of in situ TEM 
He implantation and subsequent in situ TEM annealing in $\mathrm{Pd}$, a face-centered cubic metal. We include a thorough discussion of how in situ ion implantation and in situ annealing data could help improve models of cavity nucleation and growth and help pursue a physics-based mechanistic understanding of noble gas behavior within solids in extreme environments.

\section{METHODS}

Palladium wire was purchased from Alfa Aesar and was annealed prior to TEM sample preparation to force preexisting voids identified near the surface to coalesce into larger voids that could not be confused with those induced by $\mathrm{He}$ implantation. To achieve this, the wire was annealed at $700^{\circ} \mathrm{C}$ for $1.5 \mathrm{~h}$ in an evacuated quartz ampoule with base pressure of $1 \times 10^{-7}$ Torr at the time of sealing. Subsequent TEM sample preparation was carried out by using the focused ion beam (FIB) method with a FEI Helios Nanolab 660. Lamellae were thinned to electron transparency with a $\mathrm{Ga}$ ion beam, with final cleaning steps utilizing a $5-\mathrm{kV}$ accelerating voltage. The FIB lift-out thickness was not measured inside the TEM but should be similar among all samples because the same sample preparation procedure was used.

Experiments were performed using an in situ ion irradiation transmission electron microscope $\left(\mathrm{I}^{3}\right.$ TEM), a $200-\mathrm{kV}$ JEOL JEM 2100 TEM. $^{38,45}$ A TVIPS $1 \mathrm{k}$ camera enabled in situ imaging. In situ He implantations were performed by accelerating $10-\mathrm{keV}^{4} \mathrm{He}^{+}$ions, produced by a $10-\mathrm{kV}$ Colutron accelerator, into the TEM. The stage was tilted $30^{\circ}$ toward the beamline to form a $60^{\circ}$ angle between the ion beam and the sample normal so that the sample faced the ion beam. The ion beam was aligned by observing ion-beam-induced luminescence (IBIL) on quartz mounted on the JEOL single-tilt TEM stage tip. The He beam spot size is nonuniform, as determined by darker (higher beam intensity) regions visible in the burn spot. The $\mathrm{He}$ beam current was measured using a Faraday cup located upstream of the TEM on the beamline. He implantation doses were determined using the Monte-Carlo based code Stopping and Range of Ions in Matter (SRIM). ${ }^{46} \mathrm{~A}$ threshold displacement energy of $34 \mathrm{eV}^{47}$ and a density of $11.9 \mathrm{~g} / \mathrm{cm}^{3}$ were used. Figure 1 shows the SRIM predicted $\mathrm{He}$ implantation profile for $10 \mathrm{keV}{ }^{4} \mathrm{He}$ into $\mathrm{Pd}$ at an angle of incidence of $0^{\circ}$ (used for ex situ implantation into a FIB lamella) and $60^{\circ}$ (used for in situ implantation) between the beam and sample normal. A beam energy of $10 \mathrm{keV}$ was selected to provide optimum He depth distribution in the TEM samples. Bright-field (BF) TEM imaging was utilized to image cavities by the Fresnel contrast method. In situ videos were recorded in an underfocus condition, with occasional overfocus images confirming the locations of cavities, as opposed to
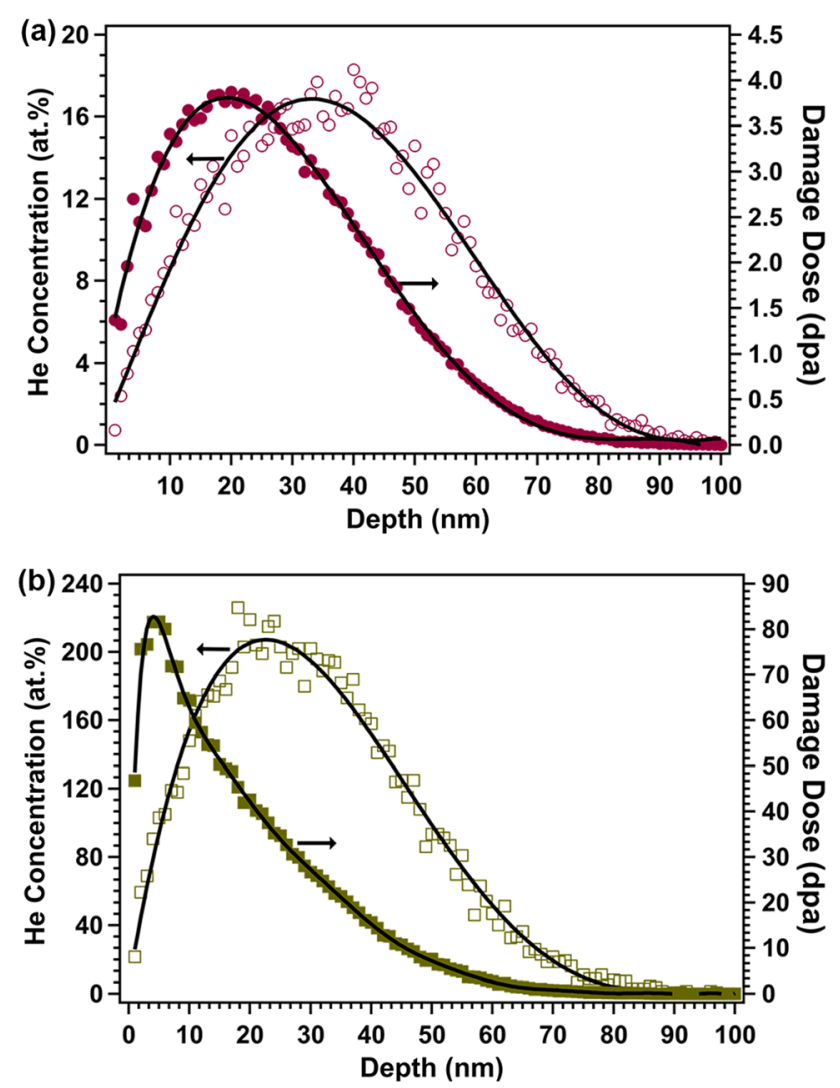

Fig. 1. SRIM-predicted He implantation and damage profile for 10$\mathrm{keV} \mathrm{He}^{+}$into $\mathrm{Pd}$ at angle of incidence of: (a) $0^{\circ}$ (used for ex situ implantation) for a fluence of $7 \times 10^{16}$ ions $/ \mathrm{cm}^{2}$ and (b) $60^{\circ}$ (used for in situ implantation) for a fluence of $1 \times 10^{18}$ ions $/ \mathrm{cm}^{2}$.

precipitates, etc. Defocus can change the apparent cavity diameter, but cavity sizes appear unchanged above $\sim 200 \mathrm{~nm}$ defocus in this material, so a high defocus value of approximately $-1 \mu \mathrm{m}$ was used for quantification of cavity size changes.

Room-temperature ex situ implantations were performed inside an external implantation chamber upstream of the TEM in the same beamline. The beam spot size was $29.4 \mathrm{~mm}^{2}$, and the ion beam current varied between $3 \mu \mathrm{A}$ and $24 \mu \mathrm{A}$ during the implantation (average $10 \mu \mathrm{A}$ or $2 \times 10^{14}$ ions $/ \mathrm{cm}^{2} /$ s). The sample was mounted in a JEOL single-tilt stage tip for implantation so that the FIB lift-out could be observed in the TEM using the same orientation after each implantation fluence. The sample was first implanted to $1 \times 10^{16}$ ions $/ \mathrm{cm}^{2}$ and imaged in the TEM. Heavy black spot damage was observed, but no cavities. The sample was implanted for an additional 9 min to reach a fluence of $7 \times 10^{16}$ ions $/ \mathrm{cm}^{2}$, after which a high density of cavities was observed under the microscope. Temperature was not controlled for beam heating during the implantation, but past measurements have shown that beam heating is lower than $50^{\circ} \mathrm{C}$. A Faraday stage to measure beam current inside the TEM was not available at the time, and no roomtemperature in situ implantation was performed to 
compare the He implantation fluence necessary for observable cavities versus the ex situ experiment. In situ fluence determination is difficult because the 10-keV He beam varies in shape and intensity daily with each operation of the Colutron and between ex situ and in situ beam alignments.

High-temperature implantations were performed in situ (inside the TEM) using a Gatan double-tilt heating stage at $250^{\circ} \mathrm{C}$ and $400^{\circ} \mathrm{C}$. Cavity nucleation and growth were recorded in bright-field TEM (underfocus condition) throughout the implantation. The He beam spot size was $40.8 \mathrm{~mm}^{2}$, and the beam flux was approximately $3 \times 10^{14}$ ions $/ \mathrm{cm}^{2} /$ $\mathrm{s}$ during the high-temperature in situ implantations. The combination of the samples being placed at the bottom of a deep well inside the Gatan heating stage and the influence of the objective lens magnetic field on the He beam likely resulted in spatially inhomogeneous beam intensity. Thus, the accuracy of the He beam fluence when implanting during direct bright-field observation is difficult to quantify beyond an order of magnitude and likely changes for each experiment due to beam profile changes.

After implantation, in situ isochronal annealing was performed inside the TEM on each sample using a Gatan double-tilt heating stage. Three separate implantation temperatures were probed: $25^{\circ} \mathrm{C}\left(T_{\mathrm{H}}=0.16\right), 250^{\circ} \mathrm{C}\left(T_{\mathrm{H}}=0.29\right)$, and $400^{\circ} \mathrm{C}$ $\left(T_{\mathrm{H}}=0.37\right)$, where $T_{\mathrm{H}}$ is the homologous temperature (absolute temperature fraction of the metal melting point). In this initial study, $T_{\mathrm{H}}$ values were kept well below 1 to reduce He diffusion to the surface, TEM foil softening, and thermal drift during implantation. Using the Gatan heating stage with Mo grids allows temperatures up to $1000^{\circ} \mathrm{C}$. During annealing, each sample was ramped in $50^{\circ} \mathrm{C}$ increments ( $30 \mathrm{~s}$ ramp time) and held for $10 \mathrm{~min}$ at each temperature. Cavity growth was recorded in bright-field (BF) TEM as a function of temperature throughout the entire experiment. Samples were annealed until they disintegrated inside the microscope, which was dependent on both temperature and the specific geometry of the sample as it evolved.

Images were drift-corrected using Adobe After Effects software. Cavity size analysis was performed using underfocus images and the "Analyze Particles" function in ImageJ. ${ }^{48}$ For most image sets, images recorded after $10 \mathrm{~min}$ of annealing were used for the analysis. Filtering steps were optimized in ImageJ for each image set and kept consistent for the entire image set. Typical filtering steps include (1) FFT bandpass, (2) Gaussian blur, (3) the "normalize local contrast" integral image filter, (4) inverting the image, (5) cropping the image to a region with uniform contrast, (6) thresholding the image, and (7) analyzing the particles. In image sets containing overlapping cavities, the objective of the image analysis was to separate enough cavities to have a representative size distribution. In those cases, many cavities could not be separated by the image analysis software, so the density could not be accurately measured. Pixel size was approximately $0.4 \mathrm{~nm}$, and the cavity diameter measurement error was assumed to be near this value, $\pm 0.5 \mathrm{~nm}$. Cavities with diameter smaller than $1 \mathrm{~nm}$ cannot be confidently identified using Fresnel contrast techniques, ${ }^{49}$ thus cavities identified by ImageJ with diameter $<1 \mathrm{~nm}$ were not included in the size distribution analysis. Cavity diameter differences due to defocus are expected to be less than the estimated $0.5 \mathrm{~nm}$ error.

\section{RESULTS}

The diffusivities of $\mathrm{He}$ atoms and of irradiationinduced point defects are temperature dependent, so cavity nucleation and growth are also temperature-dependent processes. We present time-dependent cavity evolution data from ex situ and in situ He implantation into TEM foils at various temperatures, and during in situ annealing.

\section{Ex Situ and In Situ He Implantation}

One Pd TEM sample was implanted ex situ at room temperature to a fluence of approximately $7 \times 10^{16}$ ions $/ \mathrm{cm}^{2}$. Nearly spherical cavities approximately $1 \mathrm{~nm}$ in diameter were identified in this sample (Fig. 2a-c). Cavities nucleated homogeneously throughout the sample with a measured areal density of $5 \times 10^{12}$ cavities $/ \mathrm{cm}^{2}$. No preferential nucleation at grain boundaries was observed. The initial cavity density is considerably high, as the measured areal spacing is on the order of the cavity diameter.

Next, samples were implanted in situ at $250^{\circ} \mathrm{C}$ and $400^{\circ} \mathrm{C}$ (Fig. $2 \mathrm{~d}-\mathrm{i}$ ). Cavity diameter and density changes as a function of He fluence are shown in Fig. 3a. Cavities are first observed at a fluence of $8 \times 10^{17}$ ions $/ \mathrm{cm}^{2}$ at $250^{\circ} \mathrm{C}$ and at a fluence of $1 \times 10^{18} \mathrm{ions} / \mathrm{cm}^{2}$ at $400^{\circ} \mathrm{C}$. Both fluences are more than an order of magnitude higher than the final ex situ implantation fluence, which resulted in a high density of similarly sized cavities. The high fluences required to achieve observable cavities at high temperature could easily be attributed to a less accurate fluence measurement and $\mathrm{He}$ diffusion to the foil surface when implanting in situ. For this reason, successful in situ experiments usually do not rely on attaining a specific fluence, but rather general microstructural changes as a function of fluence. At elevated temperature, cavities nucleate both inside the grains and at the grain boundaries. Cavity diameter remained approximately $1 \mathrm{~nm}$ throughout the implantation at both temperatures. Cavity density increased with fluence at rates of $2 \times 10^{-6}\left(\right.$ cavities $\left./ \mathrm{cm}^{2}\right) /\left(\right.$ ion $\left./ \mathrm{cm}^{2}\right)$ for $250^{\circ} \mathrm{C}$ implantation and of $9 \times 10^{-7}\left(\right.$ cavities $\left./ \mathrm{cm}^{2}\right) /\left(\right.$ ion $\left./ \mathrm{cm}^{2}\right)$ for $400^{\circ} \mathrm{C}$ implantation, as determined from the slope of linear fits to the density data in Fig. 3a. The slightly slower increase in cavity density at $400^{\circ} \mathrm{C}$ could be 


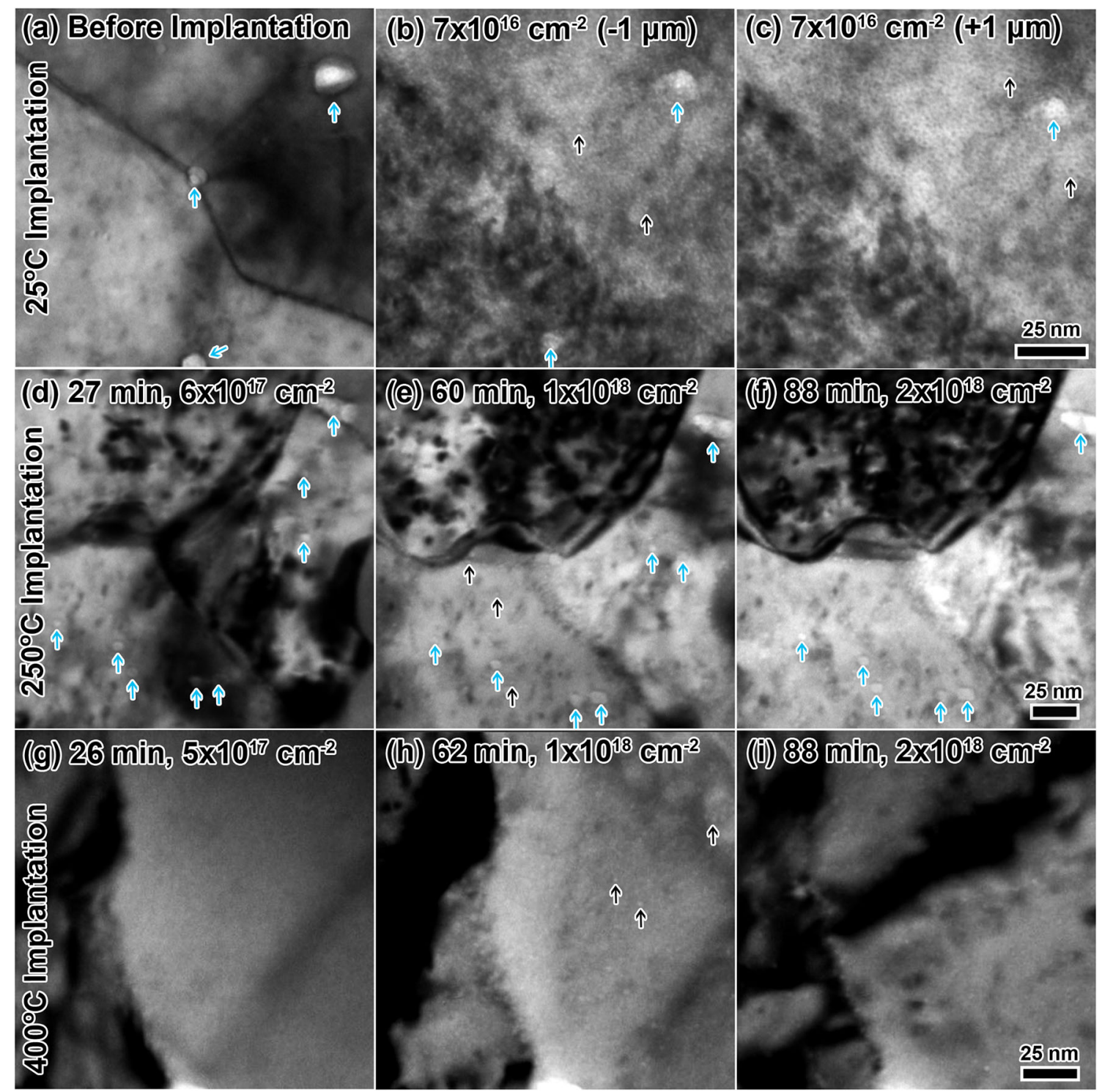

Fig. 2. BF TEM micrographs (approximately $-1 \mu \mathrm{m}$ defocus) showing cavity evolution during (a-c) ex situ He implantation into a TEM foil at room temperature, and during in situ $\mathrm{He}$ implantation at $(\mathrm{d}-\mathrm{f}) 250^{\circ} \mathrm{C}$ and $(\mathrm{g}-\mathrm{i}) 400^{\circ} \mathrm{C}$. Black arrows indicate examples cavities formed by implantation; blue arrows indicate all preexisting voids in the field of view (Color figure online).

attributed to increased He diffusion to free surfaces but is likely within error of the fluence measurement (currently unknown). Cavity densities measured in both samples implanted in situ at high temperature are low compared with the sample implanted ex situ at room temperature, which had too many overlapping bubbles to allow density quantification in Fig. 3.

\section{In Situ Annealing}

Images after each isochronal annealing step (labeled "Fig. S\#") and pertinent video files (labeled "Supplementary Video \#") are provided in the Supplementary Files. Please note that Supplementary Videos are accelerated 12x. First, the sample implanted ex situ at $25^{\circ} \mathrm{C}$, containing a high initial cavity density (Fig. 4a), was annealed. The TEM micrographs do not show a substantial increase in either intragranular or grain boundary cavity size until $300^{\circ} \mathrm{C}$, where cavity growth occurs near grain boundaries. At $350^{\circ} \mathrm{C}$ (Fig. $4 \mathrm{~b}$ ), cavities located along the grain boundaries are significantly larger (approximately $8 \mathrm{~nm}$ to $12 \mathrm{~nm}$ in diameter) than cavities located inside the grains (approximately $1.8 \mathrm{~nm}$ in diameter). Cavities located at the grain boundaries are elongated in the direction of the grain boundary. This change is barely detectable in the image analysis data shown in Fig. 3b, which shows the mean measured cavity size for the entire image. Numerous 1-nm to 2 -nm cavities are present in all annealing images for this sample. Video indicates that, at this temperature, cavity growth at the grain boundary occurred due to coalescence of nearby cavities along the grain boundary, which 

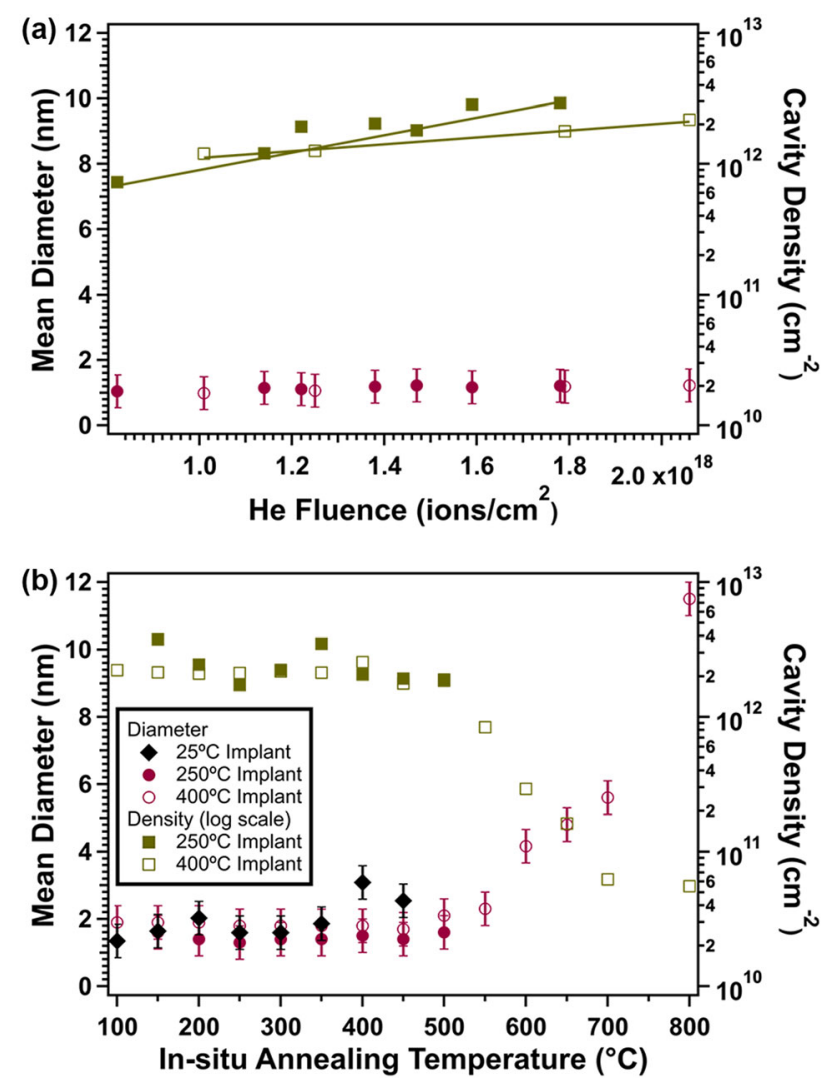

Fig. 3. Measured cavity density (green squares) and diameter (red circles or black diamonds) changes as a function of (a) implantation fluence in samples implanted in situ at $250^{\circ} \mathrm{C}$ and $400^{\circ} \mathrm{C}$ and (b) in situ annealing temperature in all samples. Cavity density is given on a log scale, as only order-of-magnitude changes are considered significant. Measurements were made after the complete isochronal annealing step. Linear fits are shown for cavity density in (a) (Color figure online).

also causes cavities to become elongated in the grain boundary direction. Additional changes are apparent at $400^{\circ} \mathrm{C}$ (Fig. 4c; Supplementary Video 1), where the cavities at grain boundaries developed facets and grew to lengths of approximately $25 \mathrm{~nm}$ to $45 \mathrm{~nm}$. Cavities grow along grain boundaries by absorbing smaller cavities present above or below them, which is visualized in transmission through the foil thickness. Additionally, cavities often spontaneously coalesce with other cavities on the grain boundary. Cavities inside the grains are either (1) large, approximately $5 \mathrm{~nm}$ to $12 \mathrm{~nm}$ in diameter and highly faceted, or (2) small, approximately $1.5 \mathrm{~nm}$ in diameter and spherical. The smaller cavities could be new cavities nucleating from $\mathrm{He}$ in the lattice, while the larger cavities formed by growth of existing voids or through coalescence with nearby cavities. An example of the coalescence mechanism observed with cavities on the grain boundary is depicted in Fig. 5 . At $450^{\circ} \mathrm{C}$, the rate of cavity coalescence increases both at the grain boundaries and inside the grains. The time required to reach a stable configuration after coalescence is greater for two large cavities than for two small cavities. Cavities located at the grain boundaries continued to grow by absorption of nearby cavities until they reach sizes near the thin-film thickness, at which point they annihilate with the surface, leaving behind a denuded zone at the grain boundary. The largest cavity is approximately $55 \mathrm{~nm}$ in width and $125 \mathrm{~nm}$ in length just before annihilation with the surface. Some smaller more spherical cavities remain in the denuded zone and diffuse through the matrix to coalesce with other cavities. After a few minutes of annealing at $450^{\circ} \mathrm{C}$, significant sample disintegration and cavity annihilation with the surface occurs, resulting in the measurable drop in mean cavity diameter (Fig. 3b).

Next, the samples implanted in situ at elevated temperatures $\left(250^{\circ} \mathrm{C}\right.$ and $\left.400^{\circ} \mathrm{C}\right)$, containing a low initial cavity density (Fig. 4d), were annealed (Supplementary Videos 2 and 3-5, respectively). Both samples behaved similarly during annealing (shown quantitatively in Fig. 3b) up to $500^{\circ} \mathrm{C}$. The sample implanted at $250^{\circ} \mathrm{C}$ was only annealed up to $500^{\circ} \mathrm{C}$ because of significant degradation past this temperature. The sample implanted at $400^{\circ} \mathrm{C}$ was annealed up to $800^{\circ} \mathrm{C}$. Overall, an increase in cavity diameter never occurs in the sample implanted at $250^{\circ} \mathrm{C}$, but in the sample implanted at $400^{\circ} \mathrm{C}$, an increase occurs at each temperature above $600^{\circ} \mathrm{C}$. Cavity density decreases at each temperature above $600^{\circ} \mathrm{C}$. Figures S2 and S3 show no visible changes during annealing in either sample until $450^{\circ} \mathrm{C}$. At $450^{\circ} \mathrm{C}$, a few cavities vibrate about their center position, apparently bounded in most cases, and adjacent cavities occasionally coalesce. In a few cases, cavities diffuse a small distance (on the order of several nanometers) in a Brownian-like motion and coalesce with more distant cavities. An example of Brownian-like cavity diffusion and coalescence is shown in Fig. 6. Similar vibratory and diffusive motion occurs at a higher rate in the videos at $500^{\circ} \mathrm{C}$. Cavities appear larger in the micrographs taken after annealing at $500^{\circ} \mathrm{C}$ (Fig. 4e), especially along grain boundaries, but the mean cavity size after the entire annealing step is not significantly different from the mean size at $450^{\circ} \mathrm{C}$ (Fig. $3 \mathrm{~b}$ ). Cavities appear considerably larger in the micrographs taken after annealing at $550^{\circ} \mathrm{C}$ (Fig. 4f), but the cavity diameter measurement is within error of that for $500^{\circ} \mathrm{C}$. At $550^{\circ} \mathrm{C}$, vibratory motion, as well as the rate and distance of Brownian-like cavity migration, increase substantially in the videos. The mean cavity diameter increases at $600^{\circ} \mathrm{C}$, as is apparent in Fig. S3. Cavity growth is primarily due to coalescence driven by the cavity diffusion mechanism first observed at $450^{\circ} \mathrm{C}$, but the rate of cavity diffusion accelerates with each increase in temperature, leading to the marked increase in mean cavity diameter in Fig. $3 \mathrm{~b}$ as the temperature is increased to $800^{\circ} \mathrm{C}$. Cavities appear to vibrate about an equilibrium position until they suddenly move from that location and begin diffusing. In some instances, perhaps due to strain fields present in the sample, the cavities do not move solely by Brownian motion but rather 

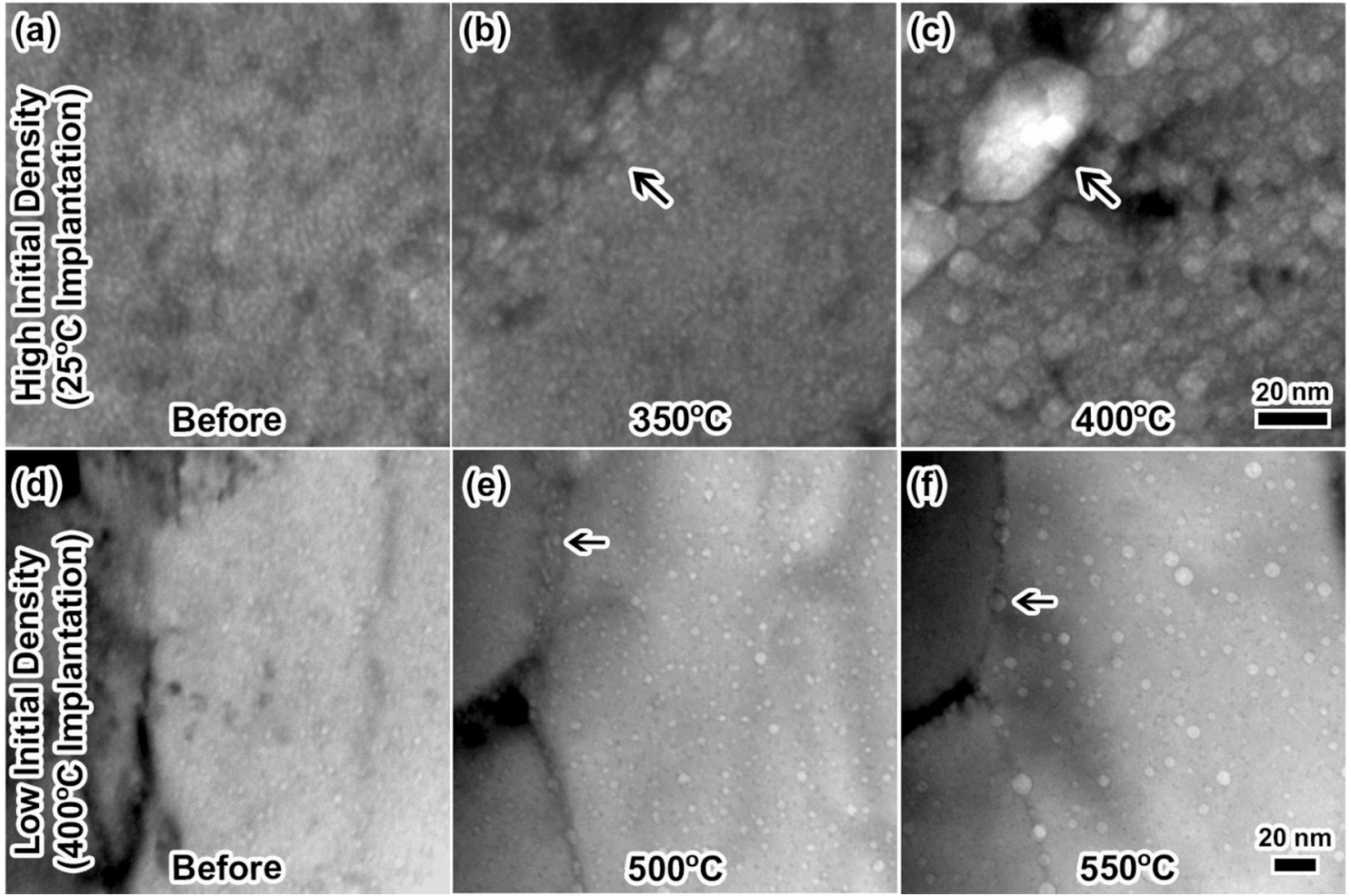

Fig. 4. BF TEM micrographs (approximately $-1 \mu \mathrm{m}$ defocus) showing an overview of cavity evolution under annealing conditions with a high (ac) and low cavity density (d-f). Arrows indicate cavity growth along grain boundaries.

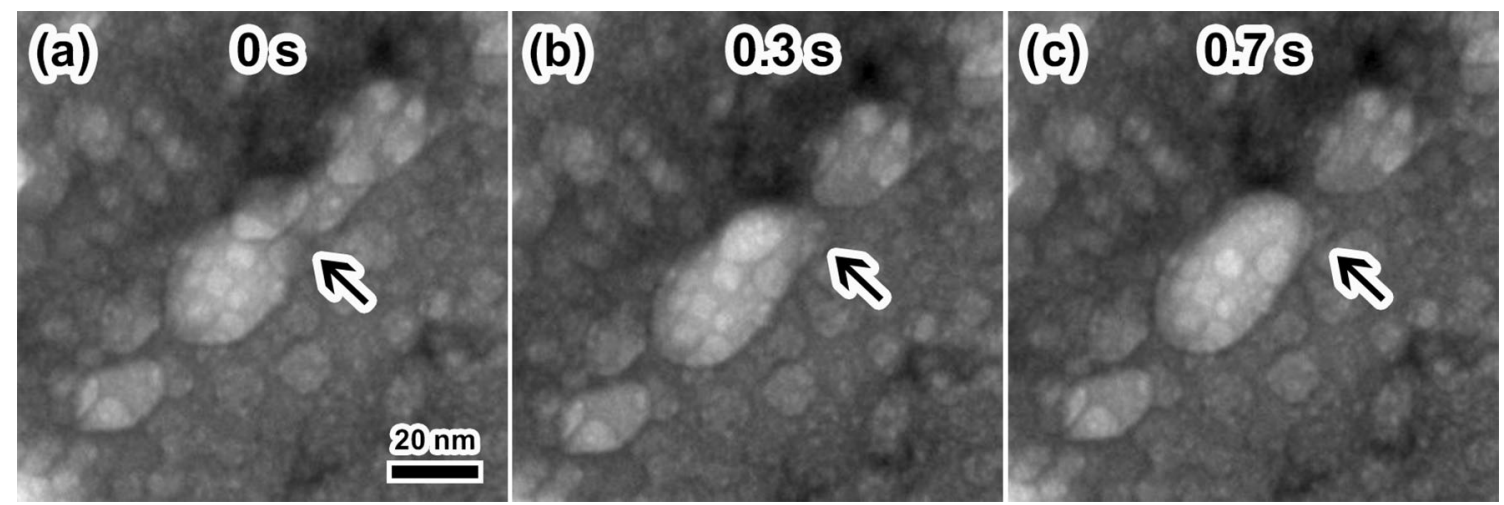

Fig. 5. BF TEM micrographs showing the cavity coalescence mechanism, occurring along a grain boundary in this case, which drives cavity growth during annealing in samples containing a high initial cavity density. Shown in the sample implanted at $25^{\circ} \mathrm{C}$ under annealing at $400^{\circ} \mathrm{C}$. The arrow indicates the region initially containing smaller cavities in (a), which begin to coalesce in (b) and are no longer present in (c) due to being fully absorbed by a larger cavity.

appear to move along a directed path. Both small and large cavities move through the solid at all temperatures, so a size dependence of cavity motion was not identified. As the cavities diffuse and coalesce to form larger cavities, the cavity density decreases, a trend that is apparent in Figs. S2 and S3 and in the image analysis data in Fig. 3b. As temperature is increased, many cavities also diffuse to the free surfaces and annihilate there, contributing to the reduction in cavity density. By $700^{\circ} \mathrm{C}$, most cavities are trapped either at grain boundaries or inside the grains and continue to vibrate about a stationary position. Cavities remained spherical throughout annealing in the samples implanted in situ at high temperature, which had a low initial cavity density.

\section{DISCUSSION}

Comparisons between the cavity evolution observed here and theoretical models offer insight into mechanisms. Below we make such comparisons as well as instances where similar behavior has been observed in other $\mathrm{He}$ implantation experiments. 


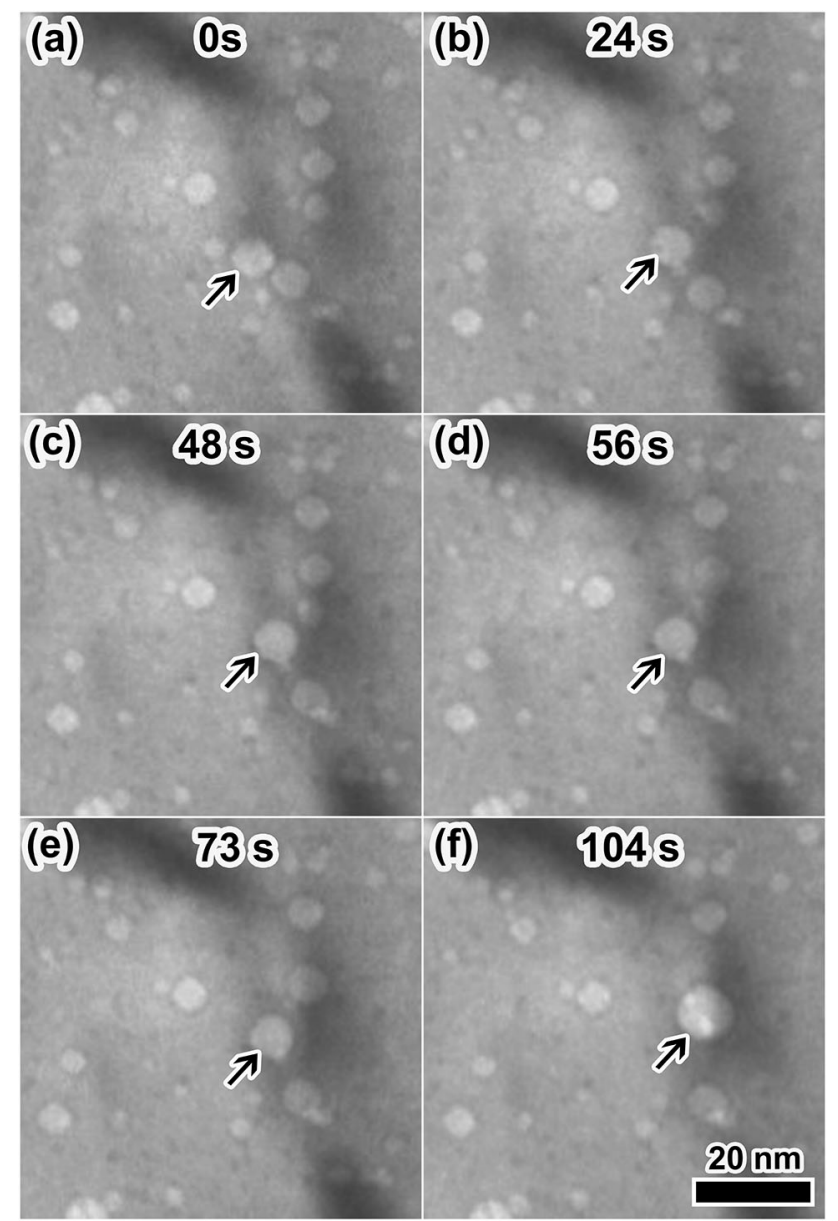

Fig. 6. BF TEM micrographs showing the mechanism of cavity migration and coalescence which drives cavity growth during annealing in samples containing a low initial cavity density. Images are from the sample implanted at $400^{\circ} \mathrm{C}$ under annealing at $550^{\circ} \mathrm{C}$. Arrows in (a-f) point to the migrating cavity.

\section{Cavity Motion}

In our annealing experiments, as best observed in Supplementary Video 4 for the sample implanted at $400^{\circ} \mathrm{C}$ and annealed at $550^{\circ} \mathrm{C}$, many but not all cavities are observed to perform random walks caused by the random thermal motion of $\mathrm{Pd}$ atoms which rearrange the surface of the cavities, causing the center of mass of the cavity to be displaced. Motions can be of metal atoms on the surface of the cavity, diffusion of vacancies or self-interstitial metal atoms surrounding the cavity which exchange with the surface, or vapor-phase transport of metal atoms through the cavity interior. A strong dependence of the mean squared displacement of a random walk on cavity radius is expected ${ }^{50,51}$ and has been at least qualitatively observed in recent work. ${ }^{52}$ The predicted dependence varies with the mechanism of $\mathrm{Pd}$ atom motion. The temperature dependence increases for these mechanisms in the listed order: both the activation energy for surface diffusion and surface defect formation energy are generally smaller than for bulk processes. The radial dependence is higher for surface diffusion than for the other mechanisms. A complicating feature compared with void migration is that generation rates of bulk defects depend on the $\mathrm{He}$ content of a cavity because the pressure induced by $\mathrm{He}$ favors creation of self-interstitial atoms and disfavors creation of vacancies, whereas there should be no such dependence on He content for diffusion of surface metal atoms.

In Supplementary Video 4 for the sample implanted at $400^{\circ} \mathrm{C}$ and annealed at $550^{\circ} \mathrm{C}$, we observed some cavities of a given size that moved rapidly and others that were immobile, so it is clear that factors other than cavity radius are significant. The cavities likely contain varying $\mathrm{He}$ concentrations and exist in an imperfect crystal that contains defects and strain fields that influence their motion. This makes correlation of the radius, temperature, and motion of a cavity difficult. We qualitatively observe that, when larger bubbles move, it is more likely to be in a directed manner than by a random walk as compared with small bubbles, which is consistent with literature models. ${ }^{50}$ Some cavities exhibited clear nonrandom motion, likely due to the influence of external (e.g., due to foil bending, nonuniform temperature fields, constraint by the sample holder) or internal (e.g., due to other cavities) stress fields. While the effects of external stress fields are undesired artifacts and difficult to characterize, the effects of internal stress fields are an important aspect of cavity evolution. These fields affect how the cavities distribute themselves and how they interact with each other and with other defects such as grain boundaries; For example, it was observed that cavities accelerated as they approached a grain boundary. Some moving cavities increased size by coalescence with other cavities and then continued their motion at an undiminished rate. Because of the complexity of bubble motion, it is difficult to narrow the list of three proposed mechanisms in this case, but this may be possible by considering other aspects of cavity behavior.

\section{Cavity Coalescence}

Similarly diverse behavior was observed during cavity-cavity coalescence events. In some cases, neighboring cavities underwent rapid coalescence, whereas in other cases, similarly spaced cavities coexisted without coalescence for much of the duration of the experiment. This could be partially, but probably not entirely, explained by differing bubble depths. Cavities interact with each other elastically over short distances in a manner that can be either attractive or repulsive, depending on orientation versus the underlying lattice, and perhaps other superimposed stress fields. ${ }^{53,54}$ Coalescence cannot proceed entirely by the mechanisms that cause cavity motion because the final step of coalescence requires creation of a distinct configuration of the surfaces of the cavities; For example, 
nucleation of a crack through the material between cavities could be necessary. Because cavities rapidly rearrange to a compact shape after coalescence, diffusion of surface atoms or nearby point defects are necessary to minimize surface energy and obtain a compact shape.

\section{Cavity Growth}

During room-temperature implantation, high cavity densities were observed where the cavity spacing is comparable to cavity size. However, at the elevated implantation temperatures studied, lower cavity densities were observed, with relatively high densities at grain boundaries, though at these temperatures, the motion and coalescence of cavities was not observed to be significant during implantation. This suggests that He atoms, vacancies, and/or clusters of these species are mobile enough at these elevated temperatures to be transported to previously nucleated cavities, whereas at room temperature, the concentration of these species is high enough to nucleate more cavities. For high-temperature implantations, Supplementary Videos 2-5 do not show spontaneous gradual growth of isolated bubbles while annealing after implantation stops, providing further evidence that He and implantation-induced vacancies are rapidly transported to bubbles at the higher implantation temperatures. When annealing above $500^{\circ} \mathrm{C}$, cavity growth seems driven instead by coalescence of existing cavities. We observed no evidence of Ostwald ripening, in which one cavity in a neighboring pair grows and the other shrinks. Because injection of He back into the lattice is highly thermodynamically unfavorable (because of the low solubility of $\mathrm{He}$ in $\mathrm{Pd}$ ), we expect $\mathrm{He}$ migration to bubbles to be irreversible.

Cavity growth by migration and coalescence has been observed using in situ TEM heating of Hecontaining samples before, including $\mathrm{Cu}$ at $800^{\circ} \mathrm{C}$ $\left(T_{\mathrm{H}}=0.8\right),{ }^{55} \mathrm{He}$-implanted $\mathrm{Al}$ at $645^{\circ} \mathrm{C}\left(T_{\mathrm{H}}=0.98\right),{ }^{40}$ He-implanted $\mathrm{Si}$ above $550^{\circ} \mathrm{C}\left(T_{\mathrm{H}}=0.5\right),{ }^{52}$ and Heimplanted V at $950^{\circ} \mathrm{C}\left(T_{\mathrm{H}}=0.6\right) .{ }^{44}$ Growth by coalescence alone has been observed in samples with a high cavity density, including $\mathrm{Al}$ during He implantation at $300^{\circ} \mathrm{C}\left(T_{\mathrm{H}}=0.6\right) .{ }^{43}$ Many researchers have previously focused on dislocation-based growth processes, where individual He filled cavities are able to grow on their own by emitting dislocations. ${ }^{56-59}$ Apparently, the cavity pressures achieved in our annealing experiments were not large enough to drive dislocation-mediated growth.

In the samples implanted at elevated temperature, most of the cavities observed were spherical and remained so during annealing. The rapid surface rearrangement of coalesced bubbles suggests that cavities assume equilibrium shapes at temperatures where coalescence occurs. It is thus interesting that the shape of the coalesced cavities seems to depend on the initial cavity density; coalesced cavities tended to be more faceted when the initial cavity density was high (Fig. 4). This would not be expected if minimization of the surface energy alone was determining the cavity shapes and if surface energy always had the same dependence on surface orientation for all the cavities. It is likely, however, that the $\mathrm{He}$ pressure of initial cavities depends on implantation conditions. We thus speculate that either pressurized $\mathrm{He}$ is affecting the surface structure of the cavities or the strain fields around the pressurized cavities are influencing their shape.

\section{CONCLUSION}

In situ TEM ion implantation and annealing are novel techniques for elucidating time-dependent mechanisms involved in noble gas-stabilized cavity evolution in extreme environments. This work used in situ TEM to quantify cavity nucleation and growth as a function of implantation time and temperature, and qualitatively characterized cavity growth mechanisms during isochronal annealing. Cavity nucleation was unsurprisingly found to be highly temperature dependent, with homogeneous nucleation occurring at $25^{\circ} \mathrm{C}$ and heterogeneous nucleation, both at grain boundaries and inside the grains, occurring at $250^{\circ} \mathrm{C}$ and $400^{\circ} \mathrm{C}$. Cavity growth mechanisms appeared to be highly dependent on the initial cavity density, with a high initial density resulting in the formation of large faceted cavities due to coalescence and a low initial density resulting in growth of spherical cavities through cavity migration and coalescence. These results suggest that He atoms and vacancies in the lattice move relatively slowly at room temperature but quickly enough at elevated temperatures to affect cavity evolution. Possible mechanisms leading to this behavior were discussed. Many opportunities exist to combine this type of experimentation with modeling to improve our understanding of cavity behavior.

\section{ACKNOWLEDGEMENTS}

Riley Parrish (SNL/NM) provided helpful discussion, and Warren York (SNL/CA) aided TEM sample preparation. K.H. was fully supported and R.S. partially supported by the US Department of Energy (DOE), Office of Basic Energy Sciences, Division of Materials Sciences and Engineering. This work was performed at the Center for Integrated Nanotechnologies, an Office of Science User Facility operated for the US DOE Office of Science. Sandia National Laboratories is a multimission laboratory managed and operated by National Technology \& Engineering Solutions of Sandia, LLC, a wholly owned subsidiary of Honeywell International, Inc., for the US DOE's National Nuclear Security Administration under Contract DE-NA-0003525. The views expressed in the article do not necessarily represent the views of the US DOE or the US Government. 


\section{OPEN ACCESS}

This article is licensed under a Creative Commons Attribution 4.0 International License, which permits use, sharing, adaptation, distribution and reproduction in any medium or format, as long as you give appropriate credit to the original author(s) and the source, provide a link to the Creative Commons licence, and indicate if changes were made. The images or other third party material in this article are included in the article's Creative Commons licence, unless indicated otherwise in a credit line to the material. If material is not included in the article's Creative Commons licence and your intended use is not permitted by statutory regulation or exceeds the permitted use, you will need to obtain permission directly from the copyright holder. To view a copy of this licence, visit $h$ ttp://creativecommons.org/licenses/by/4.0/.

\section{ELECTRONIC SUPPLEMENTARY MATERIAL}

The online version of this article (https://doi.org/ 10.1007/s11837-020-04117-4) contains supplementary material, which is available to authorized users.

\section{REFERENCES}

1. J. Rest, Nucl. Technol. 61, 33-48 (1983).

2. N. Yoshida, H. Iwakiri, K. Tokunaga, and T. Baba, J. Nucl. Mater. 337-339, 946-950 (2005).

3. E.E. Bloom and F.W. Wiffen, J. Nucl. Mater. 58, 171-184 (1975).

4. A.A. Sagues, H. Schroeder, W. Kesternich, and H. Ullmaier, J. Nucl. Mater. 78, 289-298 (1978).

5. H. Trinkaus and B.N. Singh, J. Nucl. Mater. 323, 229-242 (2003).

6. P. Hosemann, Scr. Mater. 143, 161-168 (2018).

7. D. Kiener, A.M. Minor, O. Anderoglu, Y. Wang, S.A. Maloy, and P. Hosemann, J. Mater. Res. 27, 2724-2736 (2012).

8. R. Liontas, X.W. Gu, E. Fu, Y. Wang, N. Li, N. Mara, and J.R. Greer, Nano Lett. 14, 5176-5183 (2014).

9. S. Taller, D. Woodley, E. Getto, A.M. Monterrosa, Z. Jiao, O. Toader, F. Naab, T. Kubley, S. Dwaraknath, and G.S. Was, Nucl. Instrum. Methods Phys. Res. B 412, 001-10 (2017).

10. G.S. Was, J.D. Demaree, V. Rotberg, and K. Kim, Surf. Coat. Technol. 66, 446-452 (1994).

11. P.B. Johnson, R.W. Thomson, and K. Reader, J. Nucl. Mater. 273, 117-129 (1999).

12. J.I. Cole and T.R. Allen, J. Nucl. Mater. 283-287, 329-333 (2000).

13. A. Hasegawa, M. Saito, S. Nogami, K. Abe, R.H. Jones, and H. Takahashi, J. Nucl. Mater. 264, 355-358 (1999).

14. K. Hattar, M.J. Demkowicz, A. Misra, I.M. Robertson, and R.G. Hoagland, Scr. Mater. 58, 541-544 (2008).

15. N.R. Catarineu, N.C. Bartelt, J.D. Sugar, S.M. Vitale, K.L. Shanahan, and D.B. Robinson, J. Phys. Chem. C 123, 19142-19152 (2019).

16. R.L. Williamson, J.D. Hales, S.R. Novascone, M.R. Tonks, D.R. Gaston, C.J. Permann, D. Andrs, and R.C. Martineau, J. Nucl. Mater. 423, 149-163 (2012).
17. C.S. Deo, M.A. Okuniewski, S.G. Srivilliputhur, S.A. Maloy, M.I. Baskes, M.R. James, and J.F. Stubbins, J. Nucl. Mater. 36, 141-148 (2007).

18. P.C. Millett, A. El-Azab, and D. Wolf, Comput. Mater. Sci. 50, 960-970 (2011).

19. R.D. Smirnov, S.I. Krasheninnikov, and J. Guteri, J. Nucl. Mater. 463, 359-362 (2015).

20. Y. Li, S. Hu, X. Sun, and M. Stan, Comput. Mater. 3, 1-17 (2017).

21. G. Pastore, L.P. Swiler, J.D. Hales, S.R. Novascone, D.M. Perez, B.W. Spencer, L. Luzzi, P. Van Uffelen, and R.L. Williamson, J. Nucl. Mater. 456, 398-408 (2015).

22. B.D. Wirth, K.D. Hammond, S.I. Krasheninnikov, and D. Maroudas, J. Nucl. Mater. 463, 30-38 (2015).

23. M.R. Tonks, D. Andersson, S.R. Phillpot, Y. Zhang, R. Williamson, C.R. Stanek, B.P. Uberuaga, and S.L. Hayes, Ann. Nucl. Energy 105, 11-24 (2017).

24. Q.M. Wei, Y.Q. Wang, M. Nastasi, and A. Misra, Philos. Mag. 91, 553-573 (2011).

25. G. Amarendra, B. Viswanathan, A. Bharathi, and K.P. Gopinathan, Phys. Rev. B 45, 10231-10241 (1992).

26. R.C. Birtcher, M.A. Kirk, K. Furuya, G.R. Lumpkin, and M.O. Ruault, J. Mater. Res. 20, 1654-1683 (2005).

27. R.W. Harrison, H. Amari, G. Greaves, J.A. Hinks, and S.E. Donnelly, MRS Adv. 1, 2893-2899 (2016).

28. C.A. Dennett, D.L. Buller, K. Hattar, and M.P. Short, Nucl. Instrum. Methods Phys. Res. B 440, 126-138 (2019).

29. C.A. Dennett, R.C. Choens, C.A. Taylor, N.M. Heckman, M.D. Ingraham, and D.B. Robinson, JOM 72, 197-209 (2019).

30. L.-F. He, M. Gupta, C.A. Yablinsky, J. Gan, M.A. Kirk, X.M. Bai, J. Pakarinen, and T.R. Allen, J. Nucl. Mater. 443, 71-77 (2013).

31. C. Chisholm, K. Hattar, and A.M. Minor, Mater. Trans. 55, 418-422 (2014).

32. O. El-Atwani, S. Gonderman, S. Suslov, M. Efe, G. De Temmerman, T. Morgan, K. Bystrov, K. Hattar, and J.P. Allain, Fusion Eng. Des. 93, 9-14 (2015).

33. B.R. Muntifering, S.J. Blair, C. Gong, A. Dunn, R. Dingreville, J. Qu, and K. Hattar, Mater. Res. Lett. 4, 96-103 (2016).

34. O. El-Atwani, J.E. Nathaniel II, A.C. Leff, J.K. Baldwin, K Hattar, and M.L. Taheri, Mater. Res. Lett 5, 195-200 (2017).

35. B.R. Muntifering, Y. Fang, A.C. Leff, A. Dunn, J. Qu, M.L Taheri, R. Dingreville, and K. Hattar, J. Nucl. Mater. 482, 139-146 (2016).

36. W. Han, M.J. Demkowicz, N.A. Mara, E. Fu, S. Sinha, A.D Rollett, Y. Wang, J.S. Carpenter, I.J. Beyerlein, and A. Misra, Adv. Mater. 25, 6975-6979 (2013).

37. C. Sun, D.C. Bufford, Y. Chen, M.A. Kirk, Y.Q. Wang, M. Li, H. Wang, S.A. Maloy, and X. Zhang, Sci. Rep. 4, 3737 (2014)

38. C.A. Taylor, D.C. Bufford, B.R. Muntifering, D. Senor, M. Steckbeck, J. Davis, B.L. Doyle, D.L. Buller, and K. Hattar, Materials 10, 1148 (2017).

39. K.J. Abrams, J.A. Hinks, C.J. Pawley, G. Greaves, J.A. van den Berg, D. Eyidi, M.B. Ward, and S.E. Donnelly, J. Appl. Phys. 111, 083527 (2012).

40. K. Ono, S. Furuno, K. Hojou, T. Kino, K. Izui, O. Takaoka, N. Kubo, K. Mizuno, and K. Ito, J. Nucl. Mater. 191-194, 1269-1273 (1992).

41. C.A. Taylor, S. Briggs, G. Greaves, A.M. Monterrosa, E. Aradi, J.D. Sugar, D.B. Robinson, K. Hattar, and J.A. Hinks, Materials 12, 2618 (2019).

42. C.D. Van Siclen and R.N. Wright, Phys. Rev. Lett. 68, 38923895 (1992).

43. S. Furuno, K. Hojou, K. Izui, N. Kamigaki, and T. Kino, J. Nucl. Mater. 155-157, 1149-1153 (1988).

44. S.K. Tyler and P.J. Goodhew, J. Nucl. Mater. 92, 201-206 (1980).

45. K. Hattar, D.C. Bufford, and D.L. Buller, Nucl. Instrum. Methods Phys. Res. B 338, 56-65 (2014).

46. J.F. Ziegler, M.D. Ziegler, and J.P. Biersack, Nucl. Instrum. Methods Phys. Res. B 268, 1818-1823 (2010). 
47. C.M. Jimenez, L.F. Lowe, E.A. Burke, and C.H. Sherman, Phys. Rev. 153, 735-739 (1967).

48. C.A. Schneider, W.S. Rasband, and K.W. Eliceiri, Nat. Methods 9, 671-675 (2012).

49. M.L. Jenkins and M.A. Kirk, Characterization of Radiation Damage by Transmission Electron Microscopy (Boca Raton: CRC Press, 2000), pp. 1-221.

50. F.A. Nichols, J. Nucl. Mater. 30, 143-165 (1968).

51. E.E. Gruber, J. Appl. Phys. 38, 243-250 (1967).

52. K. Ono, M. Miyamoto, H. Kurata, M. Haruta, and A. Yatomi, J. Appl. Phys. 126, 135104 (2019).

53. F. Chalon and F. Montheillet, J. Appl. Mech. 70, 789-798 (2003).

54. R. Shneck, R. Alter, A. Brokman, and M.P. Dariel, Philos. Mag. A 65, 797-814 (1992).
55. R.S. Barnes and D.J. Mazey, Proc. R. Soc. A 275, 47-57 (1963).

56. W.G. Wolfer, Philos. Mag. A 58, 285-297 (1988).

57. J.H. Evans, A. Van Veen, and L.M. Caspers, Scr. Metall. 15, 323-326 (1980).

58. J.H. Evans, A. Van Veen, and L.M. Caspers, Scr. Metall. 17, 549-553 (1983).

59. W.G. Wolfer, Philos. Mag. A 59, 87-103 (1989).

Publisher's Note Springer Nature remains neutral with regard to jurisdictional claims in published maps and institutional affiliations. 